\title{
Anemia in type 2 diabetic patients and correlation with kidney function in a tertiary care sub-Saharan African hospital: a cross-sectional study
}

Vitalis F. Feteh ${ }^{1,2}$, Simeon-Pierre Choukem ${ }^{1,2,3^{*}}$, Andre-Pascal Kengne ${ }^{4}$, Daniel N. Nebongo ${ }^{2}$ and Marcelin Ngowe-Ngowe ${ }^{5}$

\begin{abstract}
Background: Anemia is common in diabetic patients and increases morbidity and mortality, but its burden has been less well characterized in sub-Saharan Africans. We determined the prevalence of anemia and investigated the related factors, with a particular focus on the role of declining renal function, in type 2 diabetic patients attending a tertiary health care institution in Cameroon.

Methods: Hemoglobin ( $\mathrm{Hb}$ ) levels were measured in a consecutive sample of patients with type 2 diabetes, who reported for annual review at the outpatient section of the Douala General Hospital in 2013. Patients were classified as anemic according to the World Health Organisation criteria $(\mathrm{Hb}<12 \mathrm{~g} / \mathrm{dl}$ for females and $\mathrm{Hb}<13 \mathrm{~g} / \mathrm{dl}$ for males). Estimated glomerular filtration rate (eGFR) was calculated using the abbreviated Modification of Diet in Renal Disease Study Group formula. Determinants of Hb concentration and anemia were investigated using multivariable logistic regressions.

Results: A total of 636 patients were examined including 263 (prevalence rate $41.4 \%$ ) who had anemia. The prevalence of anemia increased significantly with deteriorating kidney function, although up to $31.9 \%$ of patients with normal kidney function had anemia. Compared with their non-anemic counterparts, anemic diabetic patients were older, had longer duration of diabetes, lower eGFR, higher prevalence of proteinuria and diabetic retinopathy (all $p<0.05)$. In multivariable logistic regressions, $\operatorname{eGFR~}(p=0.001)$ and presence of retinopathy $(p=0.023)$ were the independent determinants of prevalent anemia.
\end{abstract}

Conclusions: The prevalence of anemia is high in type 2 diabetic patients attending referral institutions in Cameroon, including among those without chronic kidney disease. Routine screening for anemia in all diabetic patients may aid early identification and correction as appropriate.

Keywords: Anemia, Chronic kidney disease, Diabetes, Estimated glomerular filtration rate, Hemoglobin, Cameroon

\footnotetext{
*Correspondence: schoukem@gmail.com

'Department of Internal medicine and Pediatrics, Faculty of Health Sciences,

University of Buea, Buea, Cameroon

${ }^{2}$ Health and Human Development (2HD) Research Group, P.O. Box 4856,

Douala, Cameroon

Full list of author information is available at the end of the article
} 


\section{Background}

Developing countries are experiencing an upsurge in the prevalence of diabetes [1], which is associated with a high risk of microvascular complications [2]. For instance, the prevalence of diabetes in Cameroon has risen from $1.1 \%$ in 1997 [3] to $5.9 \%$ in 2013 [1]. It is expected that the prevalence of long-term complications of diabetes will increase accordingly due to low awareness of the disease [1] and suboptimal management of those with diagnosed diabetes [4]. Among the chronic microvascular diabetes complications, diabetic nephropathy may present with anemia at different stages of deterioration of the kidney function [5]. Accordingly, anemia is a common feature in diabetes, with a reported prevalence of $13 \%$ in a European population [6], $23 \%$ in an Australian population [7] and up to $46.5 \%$ in a Caribbean population [8].

Chronic kidney disease (CKD) does not explain all cases of anemia in diabetes, which seems to result from an interplay between several factors that include: declining kidney function, functional erythropoietin deficiency, nutritional deficiencies, chronic inflammation, iatrogenic causes, and infectious diseases [9]. As a consequence, anemia tends to occur early in diabetic patients, even in the absence of overt nephropathy, and it is more severe [10]. This is largely unrecognized by both physicians and patients despite the fact that anemia negatively affects the quality of life of diabetic patients [11]. Anemia is also a significant adverse prognostic factor for cardiovascular disease, and all-cause mortality in people with diabetes [12]. Early identification and correction of anemia has been shown to reduce the rate of progression and even delay the onset of some microvascular complications [13] as well as improve the quality of life of diabetic patients [14].

Current guidelines on the management of diabetes do not recommend routine screening for anemia. Although reports on the prevalence and predictors of anemia in diabetic patients exists elsewhere, such information is very rare in sub-Saharan Africa where other potential contributory factors like infectious and genetic diseases as well as nutritional deficiencies are very frequent and likely to worsen the burden of anemia. This study aimed to assess the prevalence and investigate the role of kidney function deterioration and other predictors of anemia in a population of type 2 diabetic patients in Cameroon.

\section{Methods}

\section{Study design, setting and population}

We conducted a cross-sectional study involving all consenting patients who were receiving chronic care for type 2 diabetes at the out-patient section of the endocrine unit of the Douala General Hospital (DGH), and covered a period of activity of 6 months from $1^{\text {st }}$
June to $31^{\text {st }}$ December 2013. DGH is a tertiary care hospital located in Douala, the economic Capital of Cameroon (approximately 2.8 million inhabitants) [15]. The endocrine unit of DGH is the main referral centre for endocrine diseases and diabetes in Douala. Patients with diabetes residing in Douala and surrounding regions were likely to receive care in this unit during the study period. Patients with diabetes receiving care in the unit undergo an annual evaluation that includes amongst others: a clinical evaluation, an assessment of diabetes control $\left(\mathrm{HbA}_{1} \mathrm{C}\right.$ level), chronic complications (fundoscopy, retinography and retinal angiography where needed; dipstick proteinuria and serum creatinine), and cardiovascular risk factors assessment. The study received ethical approval from the Institutional review board of the Faculty of Health Sciences, University of Buea, and administrative clearance from the authorities of the DGH. Patients with diagnosed type 2 diabetes, irrespective of gender and aged 20 years or above, were included. All patients with a known hematologic disease, any acute condition, or those who received a blood transfusion in the preceding 4 months were excluded.

\section{Data collection and laboratory procedures}

For each consenting patient, data were collected on medical and family history, and behavioral factors (smoking, physical exercise and alcohol consumption). The weight, height, blood pressure, waist and hip circumferences were measured using standardized methods. The body mass index (BMI) was calculated as weight (in kilograms)/height $\times$ height (in meters).

The hemoglobin level was obtained from the full blood count performed by an automated analyser (Ruby Cell Dyn, Abbott). The Jaffe method was used to measure serum creatinine levels using a Roche - Hitachi Cobas C311 analyser. Standard laboratory procedures were used in the measurement of $\mathrm{HbA}_{1} \mathrm{c}$ (immuno-turbidimetric method) and lipid profile (enzymatic method). Proteinuria was determined by dipstick.

\section{Definitions}

Patients were classified as anemic according to the World Health Organization (WHO) criteria $(\mathrm{Hb}<12 \mathrm{~g} /$ $\mathrm{dl}$ for females and $<13 \mathrm{~g} / \mathrm{dl}$ for males) [16]. A second definition of anemia was also used based on the suggested threshold of $\mathrm{Hb}<11 \mathrm{~g} / \mathrm{dl}$ (for both sexes) for the initiation of treatment with erythropoietin for anemia in chronic kidney disease [17]. Based on mean corpuscular volume (MCV), anemia was classified as microcytic $(\mathrm{MCV}<80 \mathrm{fl})$, normocytic (MCV between 80 and $100 \mathrm{fl}$ ) or macrocytic (MCV > $100 \mathrm{fl})$. Mean corpuscular hemoglobin concentration (MCHC) was used to characterize anemia as hypochromic $(\mathrm{MCHC}<32 \mathrm{~g} / \mathrm{dl})$, or normochromic ( $\mathrm{MCHC} \geq 32 \mathrm{~g} / \mathrm{dl}$ ). Estimated glomerular 
filtration rate (eGFR) $\left(\mathrm{ml} / \mathrm{min} / 1.73 \mathrm{~m}^{2}\right)$ was calculated using the abbreviated Modification of Diet in Renal Disease (MDRD) Study Group formula as eGFR $=186 \times$ [serum creatinine $(\mathrm{mg} / \mathrm{l})]^{-1.154} \times$ age $($ years $\left.)\right]^{-0.203} \times$ $0.192 \times(0.742$ for female) [18]. Based on eGFR $(\mathrm{ml} / \mathrm{min} /$ $1.73 \mathrm{~m}^{2}$ ), patients were further classified into the five stages of chronic kidney disease (CKD) as follows: stage 1 (eGFR 290 ); stage 2 (eGFR between 60 and 89); stage 3 (eGFR between 30 and 59); stage 4 (eGFR between 15 and $29)$ and stage $5($ eGFR < 15) $[17,18]$.

\section{Statistical analysis}

Data were analyzed using SAS/STAT v.9.1 for Windows (SAS Institute Inc., Cary, NC, USA). We used the chi squared test for comparison of categorical variables, and the Student $t$-test or Kruskal-Wallis test for continuous variables. Results are presented as count (percentages), mean and standard deviation (SD) or median and $25^{\text {th }}$ $75^{\text {th }}$ percentiles as appropriate. Pearson correlation was used to assess univariate associations between continuous variables. Multivariable logistic regressions were used to identify determinants of anemia; odd ratio (OR) with $95 \%$ confidence intervals (CI) are presented. A $p$-value $<0.05$ was used to characterize statistically significant results.

\section{Sample size estimation}

The sample size was estimated assuming a prevalence of anemia of $40 \%$ based on a previous study in people with diabetes in Nigeria [19], a precision of $5 \%$ and a $\mathrm{z}$ value of 1.96. Based on these assumptions a minimum of 370 participants was required.

\section{Results}

\section{General characteristics of participants}

We included 636 type 2 diabetic patients ( $53.1 \%$ males) aged 20 to 86 years (mean age $56.5 \pm 10.6$ years), with a median known duration of diabetes of 4 years $\left(25^{\text {th }}-75^{\text {th }}\right.$ percentiles, 1-9). Compared with males, females were more likely to be overweight or obese $(76.1 \%$ vs. $70.1 \%$, $p=0.042$ ), had poorer diabetes control based on mean HbA1c ( $8.5 \%$ vs. $8.1 \%, p=0.046)$ and were less likely to be current smokers ( $4.4 \%$ vs. $15.9 \%, p<0.001)$ (Table 1$)$. Other baseline characteristics of the participants are summarized in Table 1.

\section{Prevalence and distribution of anemia}

The mean hemoglobin $(\mathrm{Hb})$ levels were $13.2 \pm 2.0 \mathrm{~g} / \mathrm{dl}$ in males and $12.3 \pm 1.5 \mathrm{~g} / \mathrm{dl}$ in females $(p<0.001)$. According to the WHO criteria, 263 patients $(41.4 \%)$ had anemia. The prevalence was $42.6 \%$ in females $(n=127)$ and $40.2 \%$ in males $(n=136)$. Using the threshold recommended for intervention $(\mathrm{Hb}<11 \mathrm{~g} / \mathrm{dl}$ for both sexes), 91 patients (14.3\%), including 48 females (prevalence $16.1 \%$ ) and 43 males (prevalence $12.7 \%$ ), had anemia.

The average mean corpuscular volume (MCV) in the total population was $86.3 \pm 7.7 \mathrm{fl}$. The difference in the distribution of mean corpuscular volume categories between patients with anemia and those without anemia was significant $(p<0.001)$, with anemic patients having more microcytosis and macrocytosis than non-anemic patients (Table 2). The average MCHC was $32.4 \pm 2.7$ in the total population. Low MCHC was more common in anemic than nonanemic participants, $103(47.3 \%)$ and 100 (38.3\%) respectively $(p=0.05)$ (Table 2$)$.

\section{Kidney function and anemia}

Proteinuria was positive in $68.4 \%(n=180)$ of patients with anemia as compared with $57.6 \%(n=215)$ of patients without anemia $(p=0.001)$. The mean eGFR of the 584 patients $(91.2 \%)$ with eGFR data was $86.2 \pm$ $31.7 \mathrm{ml} / \mathrm{min} / 1.73 \mathrm{~m}^{2}$. Patients with anemia had lower mean eGFR than patients without anemia $(72.9 \pm 35.7$ vs. $\left.89.6 \pm 29.5 \mathrm{ml} / \mathrm{min} / 1.73 \mathrm{~m}^{2}, p<0.001\right)$, and the Pearson correlation coefficient between the eGFR and the hemoglobin level was $0.29(p<0.001)$ (Fig. 1).

Two hundred and fifty $(42.8 \%)$ participants had normal kidney function (eGFR $\geq 90 \mathrm{ml} / \mathrm{min} / 1.73 \mathrm{~m}^{2}$ ) among whom 80 (31.9\%) were anemic compared with $160(48.0 \%)$ in patients with any CKD $(p<0.001)$. As kidney function deteriorated, the prevalence of anemia increased (Fig. 2). Compared with patients with normal eGFR, patients with CKD (eGFR $<90 \mathrm{ml} / \mathrm{min} / 1.73 \mathrm{~m}^{2}$ ) of any degree were about two times more likely to have anemia at levels where treatment was required.

Among the 108 (18.5\%) patients with chronic renal failure (CRF) $\left(\mathrm{eGFR}<60 \mathrm{ml} / \mathrm{min} / 1.73 \mathrm{~m}^{2}\right), 40(37.0 \%)$ had anemia at levels requiring therapeutic intervention, about four times higher than the $9.7 \%$ in patients without CRF $(p<0.001)$.

\section{Other determinants of hemoglobin levels and anemia}

Correlation coefficients between continuous variables and hemoglobin levels are shown in Table 3. Age, known duration of diabetes, systolic and diastolic blood pressure levels and serum creatinine were inversely correlated with hemoglobin levels, while waist and hip circumference, fasting glucose, HbA1c, and triglycerides were positively correlated with hemoglobin levels.

In multivariable logistic regressions, only eGFR [OR: 1.01 (95\% CI 1.00-1.02) per unit higher eGFR; $p=$ 0.001 ] and the presence of diabetic retinopathy [OR: 2.32 (95\% CI 1.39-3.85); $p=0.023$ ] were independent determinants of anemia. 
Table 1 General characteristics of participants

\begin{tabular}{|c|c|c|c|c|}
\hline Variables & Women $(n=298)$ & Men $(n=338)$ & $p$-value & Total $(n=636)$ \\
\hline Mean age (years) & $57.6 \pm 11.5$ & $55.6 \pm 9.7$ & 0.190 & $56.5 \pm 10.6$ \\
\hline Smoking & $13(4.4)$ & $53(15.9)$ & $<0.001$ & $66(10.4)$ \\
\hline Body mass index $\left(\mathrm{kg} / \mathrm{m}^{2}\right)$ & $30.5 \pm 6.6$ & $28.2 \pm 5.1$ & $<0.001$ & $29.3 \pm 14.7$ \\
\hline Overweight or obese (BMl $\geq 25 \mathrm{~kg} / \mathrm{m}^{2}$ ) & $228(76.5)$ & $237(70.1)$ & 0.042 & $465(73.3)$ \\
\hline Obese $\left(\mathrm{BMI} \geq 30 \mathrm{~kg} / \mathrm{m}^{2}\right)$ & $124(44.6)$ & $100(32.1)$ & 0.009 & $224(38.4)$ \\
\hline Waist circumference (cm) & $97.3 \pm 12.4$ & $98.7 \pm 12.9$ & 0.167 & $98.0 \pm 12.7$ \\
\hline Hip circumference (cm) & $108.4 \pm 13.3$ & $102.8 \pm 10.7$ & $<0.001$ & $105.4 \pm 12.3$ \\
\hline Abdominal obesity ${ }^{a}$ & $252(84.6)$ & $198(58.6)$ & $<0.001$ & $450(70.8)$ \\
\hline Systolic blood pressure (mmHg) & $136.2 \pm 21.1$ & $137.7 \pm 22.4$ & 0.339 & $137.0 \pm 21.8$ \\
\hline Diastolic blood pressure (mmHg) & $82.4 \pm 12$ & $82.1 \pm 12.6$ & 0.764 & $82.3 \pm 12.3$ \\
\hline Hypertension & $188(63.3)$ & $206(61.0)$ & 0.542 & $394(62.2)$ \\
\hline Any BP-lowering medication & $168(56.4)$ & $184(54.4)$ & 0.576 & $352(55.3)$ \\
\hline ACEI/ARB & $145(48.7)$ & $163(48.2)$ & 0.575 & $308(48.4)$ \\
\hline Diuretics & $104(34.9)$ & $114(33.7)$ & 0.654 & $218(34.3)$ \\
\hline Calcium channel blockers & $72(24.2)$ & $68(20.1)$ & 0.129 & $140(22.0)$ \\
\hline Beta blockers & $7(2.3)$ & $6(1.8)$ & 0.410 & $13(2.0)$ \\
\hline Use of metformin & $244(81.9)$ & $268(79.3)$ & 0.696 & $512(80.5)$ \\
\hline Use of sulfonylureas & $172(57.7)$ & $192(56.8)$ & 0.585 & $364(57.2)$ \\
\hline Use of Acarbose & $6(2.0)$ & $8(2.4)$ & 0.335 & $14(2.2)$ \\
\hline Use of Insulin & $31(10.4)$ & $37(10.9)$ & 0.383 & $68(10.7)$ \\
\hline $\mathrm{HbA} 1 \mathrm{c}(\%)$ & $8.5 \pm 2.6$ & $8.1 \pm 2.5$ & 0.046 & $8.6 \pm 2.5$ \\
\hline Fasting capillary glucose (mg/dl) & $150 \pm 60$ & $140 \pm 60$ & 0.646 & $150 \pm 60$ \\
\hline Any diabetic retinopathy & $52(22.4)$ & $83(30.4)$ & 0.080 & $135(26.7)$ \\
\hline Any diabetic nephropathy & $83(31.6)$ & $128(40.9)$ & 0.020 & $211(36.6)$ \\
\hline Any diabetic neuropathy & $141(51.1)$ & $165(52.4)$ & 0.821 & $306(51.7)$ \\
\hline Serum Creatinine (mg/dl) & $0.93 \pm 0.36$ & $1.22 \pm 0.58$ & $<0.001$ & $1.08 \pm 0.47$ \\
\hline $\operatorname{eGFR}\left(\mathrm{ml} / \mathrm{min} / 1.73 \mathrm{~m}^{2}\right)$ & $86.2 \pm 30.4$ & $86.2 \pm 32.0$ & $\geq 0.999$ & $86.2 \pm 31.7$ \\
\hline
\end{tabular}

Data are presented as number (\%) or mean \pm standard deviation;

Abbreviations: $A C E I$ angiotensin-converting enzyme inhibitor, $A R B$ angiotensin receptor blocker, $B M I$ body mass index, $B P$ blood pressure, $e G F R$ estimated glomerular filtration rate, $\mathrm{HbA1c}$ glycated hemoglobin

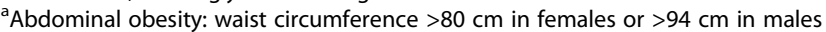

Table 2 Comparison of red cell parameters categories between anemic and non-anemic patients

\begin{tabular}{|c|c|c|}
\hline Variable & $\begin{array}{l}\text { Anemia }^{a} \\
(n=263)\end{array}$ & $\begin{array}{l}\text { No anemia } \\
(n=373)\end{array}$ \\
\hline Normocytosis* (MCV 80-100 fl) & 73.3 & 82.1 \\
\hline Microcytosis* $(\mathrm{MCV}<80 \mathrm{fl})$ & 21.4 & 15.1 \\
\hline Macrocytosis* (MCV > $100 \mathrm{fl})$ & 5.4 & 2.9 \\
\hline Normochromia (MCHC 32-36 g/dl) & 52.8 & 61.7 \\
\hline Hypochromia (MCHC $<32 \mathrm{~g} / \mathrm{dl}$ ) & 47.3 & 38.3 \\
\hline
\end{tabular}

${ }^{a}$ Anemia defined as hemoglobin concentration $<12 \mathrm{~g} / \mathrm{dl}$ for females and $<13 \mathrm{~g} / \mathrm{dl}$ for males

${ }^{*} p$ value $<0.05$

\section{Discussion}

In this study, we found that two in five patients with type 2 diabetes had anemia. This high prevalence was mainly driven by diabetes complications, as the presence of retinopathy and declining kidney function were the independent determinants of anemia. We also observed that one third of diabetic patients with normal kidney function had anemia.

Anemia is a common finding in patients with diabetes and has a negative impact on the patient's sense of wellbeing; it also impairs the ability to work, reduces the quality of life [20] and worsens cardiovascular health [12]. The prevalence of anemia in our study (41.4\%) was relatively higher than that reported in the general adult population in Cameroon (34\%) [21]. The prevalence of 


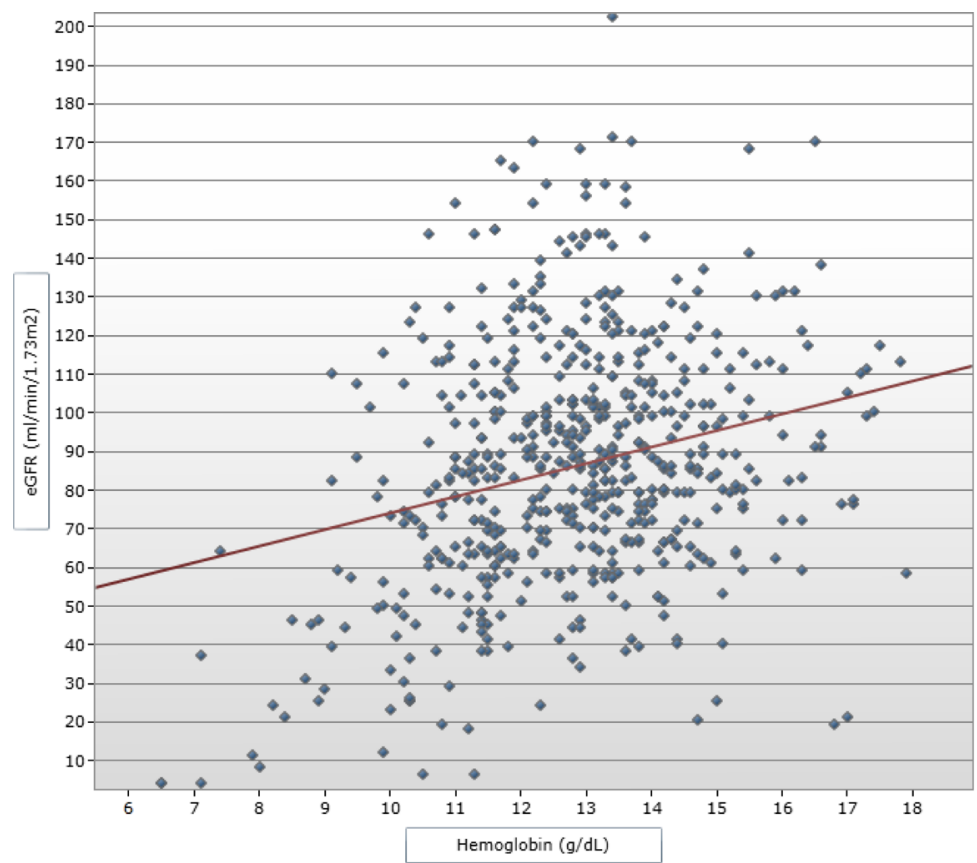

$r=0.29$

Hb $\times$ eGFR

atinear Regression

Fig. 1 Correlation between the hemoglobin level and the estimated glomerular filtration rate. Squares represent individual hemoglobin levels of participants. The red line is the linear regression line

anemia in diabetic patients reported elsewhere is comparable to, or lower than our finding, depending on the level of development of the country, the geographical altitude and the age of the study population: $46.5 \%$ in Caribbean population [8], $17 \%$ in Ethiopia [22] and 12 [6] to $23 \%$ [7] in Caucasians. The higher altitude in Ethiopia and their younger study population may account for the lower prevalence, whereas the high prevalence of infectious causes and nutritional deficiencies, asymptomatic inherited hemoglobinopathies, and suboptimal glycemic control in our population could explain the higher prevalence in the present study compared with Caucasians [23]. The high prevalence of microcytosis in our study suggests the importance of non-renal causes of anemia in diabetes patients in this setting. This may have implications on the management options. However, further research is needed to fully investigate the spectrum of the etiology of anemia in African populations with diabetes.

In Cameroon, the prevalence CKD is about $13.2 \%$ in the adult population, with the rate being higher amongst rural dwellers, and risk factors profile being similar to

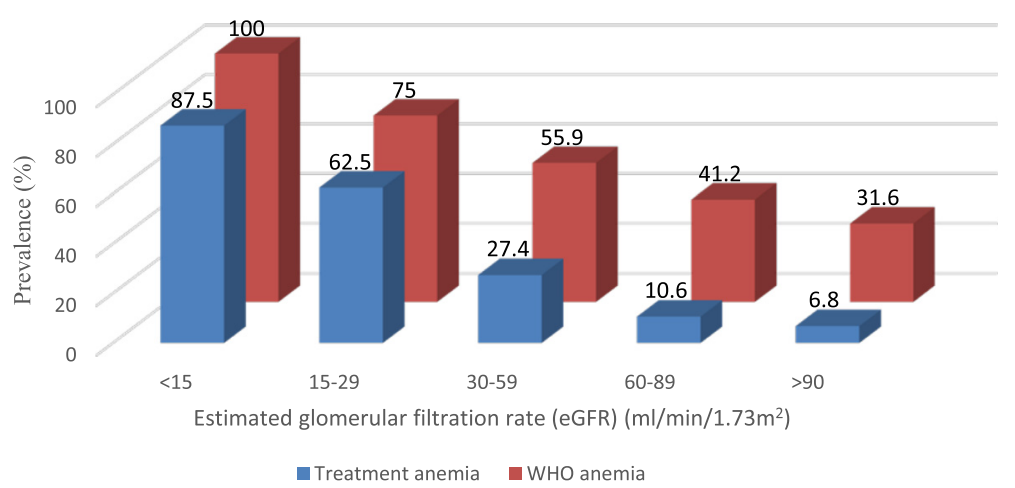

Fig. 2 Prevalence of anemia by estimated glomerular filtration rate categories. Red bars represent anemia based on the World Health Organization definition; blue bars represent anemia based on threshold for intervention. Numbers above the bars denote the prevalence of anemia in each category of estimated glomerular filtration rate 
Table 3 Correlation between hemoglobin level and other variables

\begin{tabular}{lll}
\hline Variable & $r$ (Pearson) & $p$ \\
\hline Age & -0.10 & 0.017 \\
Duration of Diabetes & -0.18 & $<0.001$ \\
Systolic BP & -0.11 & 0.005 \\
Diastolic BP & -0.10 & 0.011 \\
Waist Circumference & 0.15 & $<0.001$ \\
Hip Circumference & 0.10 & 0.040 \\
eGFR & 0.29 & $<0.001$ \\
Fasting Blood Sugar & 0.16 & $<0.001$ \\
HbA1C & 0.12 & 0.009 \\
Triglyceride & 0.15 & $<0.001$ \\
Serum Creatinine & -0.07 & $<0.001$ \\
\hline Abbreviations: BP blood pressure, eGFR estimated glomerular filtration rate
\end{tabular}

those in Caucasian populations [24]. In accordance with previous studies $[6-8,10,22,25]$ our findings illustrate the negative role of renal function decline in the development and progression of anemia in patients with diabetes. However, the absence of overt kidney disease was not protective against anemia, as $31.9 \%$ of patients with normal eGFR had anemia; this proportion is high when compared with findings in other populations-13\% in China [25]. This observation emphasizes the role of other aforementioned contributors to anemia in diabetic patients in Cameroon.

Our finding that retinopathy was a significant determinant of anemia is in line with previous reports in India [26]. This is probably because diabetes retinopathy is usually associated with diabetes nephropathy. However, anemia may in turn play a pervasive role on the microvascular complications [27]. Although HbA1c was not an independent determinant of anemia, patients with normal hemoglobin levels had significantly higher level of HbA1c than anemic patients, as observed by other authors [25]. This raises caution in interpreting HbA1c levels in diabetic patients in Africa, as anemia has also been shown to spuriously lower HbA1c [28].

We acknowledge the following potential limitations of our study. Since it was conducted in a tertiary care hospital, results may overestimate the actual burden of anemia in diabetic patients in primary healthcare. Also this study was not designed to identify the causes of anemia in diabetic patients, indicating the need for further research in this domain. The reticulocyte count and the role of chronic inflammation on prevalent anemia was not assessed, and the presence of hemoglobinopathies was not investigated. However, we had a relatively large sample size of routinely monitored type 2 diabetic patients and we used robust statistical tests to identify the determinants.

\section{Conclusions}

In conclusion, the prevalence of anemia in the type 2 diabetic population in Cameroon is high, including in patients with normal kidney function. However, declining kidney function appears as the main determinant. Our findings suggest that patients with diabetes should be routinely screened for anemia, and have other non-renal causes checked. Further, the findings raise issues regarding the added economic burden to diabetic patients attributable to anemia, and the cautious interpretation of the HbA1c level in sub-Saharan Africans.

\section{Abbreviations}

BMI: body mass index; Cl: confidence interval; CKD: chronic kidney disease; DGH: Douala General Hospital; eGFR: estimated glomerular filtration rate; $\mathrm{Hb}$ : hemoglobin; HbA1c: glycated hemoglobin; MCHC: mean corpuscular hemoglobin concentration; MCV: mean corpuscular volume; MDRD: modification of diet in renal disease; OR: odds ratio; WHO: World Health Organization.

\section{Competing interest}

The authors declare no competing interest relevant to this article.

\section{Authors' contributions}

VFF: study conception and design, data collection and analysis, draft of the manuscript. SPC: study conception and design, data collection and analysis, draft of the manuscript. APK: study design, analysis of data and drafting of the manuscript. DNN: data analysis and interpretation, editing and reviewing the manuscript. MNN: study conception and design, data collection and analysis, draft of the manuscript. All authors made significant intellectual contributions and have read, reviewed the manuscript, and approved the final manuscript.

\section{Acknowledgements}

We are grateful to all patients who accepted to participate in this study, and to the nurse staff of the outpatient Diabetes and Endocrine clinic of the Douala General Hospital. The 2HD Research Group is supported by a Cruddas Link Fellowship (SPC), Harris Manchester College, University of Oxford, UK, and receives technically support from the NIHR-Bristol Biomedical Research Unit (BRU) in Nutrition, University of Bristol, UK.

\section{Author details}

'Department of Internal medicine and Pediatrics, Faculty of Health Sciences, University of Buea, Buea, Cameroon. ${ }^{2}$ Health and Human Development (2HD) Research Group, P.O. Box 4856, Douala, Cameroon. ${ }^{3}$ Diabetes and Endocrine Unit, Department of Internal Medicine, Douala General Hospital, Douala, Cameroon. ${ }^{4}$ South African Medical Research Council, and University of Cape Town, Cape Town, South Africa. ${ }^{5}$ Department of Surgery, Obstetric and Gynecology, Faculty of Health Sciences, University of Buea, Buea, Cameroon.

Received: 7 March 2015 Accepted: 17 March 2016

Published online: 19 March 2016

\section{References}

1. IDF Diabetes Atlas sixth edition. Brussels: International Diabetes Federation; 2013. [https://www.idf.org/sites/default/files/EN_6E_Atlas_Full_0.pdf]. Accessed 12 Dec 2015.

2. Mbanya J-C, Sobngwi E. Diabetes in Africa. Diabetes microvascular and macrovascular disease in Africa. J Cardiovasc Risk. 2003;10:97-102.

3. Mbanya JCN, Ngogang J, Salah JN, Minkoulou E, Balkau B. Prevalence of NIDDM and impaired glucose tolerance in a rural and an urban population in Cameroon. Diabetologia. 1997;40:824-9.

4. Choukem SP, Fabreguettes C, Akwo E, Porcher R, Nguewa JL, Bouche C, Kaze FF, Kengne AP, Vexiau P, Mbanya JC, Sobngwi E, Gautier J-F. Influence of migration on characteristics of type 2 diabetes in sub-Saharan Africans. Diabetes Metab. 2014;40:56-60. 
5. Bosman DR, Winkler AS, Marsden JT, Macdougall IC, Watkins PJ. Anemia with erythropoietin deficiency occurs early in diabetic nephropathy. Diabetes Care. 2001;24:495-9.

6. Cawood TJ, Buckley U, Murray A, Corbett M, Dillon D, Goodwin B, Sreenan S. Prevalence of anaemia in patients with diabetes mellitus. Ir J Med Sci. 2006;175:25-7.

7. Thomas MC, Maclsaac RJ, Tsalamandris C, Molyneaux L, Goubina I, Fulcher $G$, Yue $D$, Jerums $G$. The burden of anaemia in type 2 diabetes and the role of nephropathy: a cross-sectional audit. Nephrol Dial Transplant. 2004;19: $1792-7$.

8. Ezenwaka CE, Jones-LeCointe A, Nwagbara E, Seales D, Okali F. Anaemia and kidney dysfunction in Caribbean type 2 diabetic patients. Cardiovasc Diabetol. 2008;7:25.

9. Angelousi A, Larger E. Anaemia, a common but often unrecognized risk in diabetic patients: a review. Diabetes Metab. 2014:41(1):18-27.

10. Craig KJ, Williams JD, Riley SG, Smith H, Owens DR, Worthing D, Cavill I, Phillips AO. Anemia and diabetes in the absence of nephropathy. Diabetes Care. 2005;28:1118-23.

11. Stevens PE, O'Donoghue DJ, Lameire NR. Anaemia in patients with diabetes: unrecognised, undetected and untreated? Curr Med Res Opin. 2003;19:395-401.

12. Kengne AP, Czernichow S, Hamer M, Batty GD, Stamatakis E. Anaemia, haemoglobin level and cause-specific mortality in people with and without diabetes. PLoS One. 2012;7, e41875.

13. Friedman EA, L'Esperance FA, Brown CD, Berman DH: Treating azotemiainduced anemia with erythropoietin improves diabetic eye disease. Kidney Int Suppl. 2003;64(Suppl 87):S57-63.

14. Drüeke TB, Locatelli F, Clyne N, Eckardt K-U, Macdougall IC, Tsakiris D, Burger H-U, Scherhag A, CREATE Investigators. Normalization of hemoglobin level in patients with chronic kidney disease and anemia. N Engl J Med. 2006;355:2071-84.

15. http://www.Statistics-Cameroon.org/downloads/La_population_du_ Cameroun_2010.pdf. Accessed 12 Dec 2015.

16. World Health Organisation. Nutritional anaemias. Report of a WHO scientific group. World Health Organ Tech Rep Ser. 1968:405:5-37.

17. $\mathrm{KDOQI}$ KDOQI clinical practice guideline and clinical practice recommendations for anemia in chronic kidney disease update of hemoglobin target. Am J Kidney Dis Off J Natl Kidney Found. 2007;50:471-530,

18. Levey AS, Bosch JP, Lewis JB, Greene T, Rogers N, Roth D. A more accurate method to estimate glomerular filtration rate from serum creatinine: a New prediction equation. Ann Intern Med. 1999;130:461-70.

19. Kagu MB, Mshelia DS. Anaemia in patients with diabetes mellitus attending regular diabetic outpatient clinic in Maiduguri, Nigeria. Niger J Health Biomed Sci. 2005;4:1-4.

20. Lundin AP. Quality of life: subjective and objective improvements with recombinant human erythropoietin therapy. Semin Nephrol. 1989;9(1 Suppl 1): 22-9.

21. World Health Organisation. WHO Global Database on Anaemia [http://who. int/vmnis/anaemia/data/database/countries/cmr_ida.pdf?ua=1]. Accessed 12 Dec 2015.

22. Abate A, Birhan W, Alemu A. Association of anemia and renal function test among diabetes mellitus patients attending Fenote selam Hospital, west Gojam, northwest Ethiopia: a cross sectional study. BMC Hematol. 2013;13:6.

23. Ahmed AT, Go AS, Warton EM, Parker MM, Karter AJ. Ethnic differences in anemia among patients with diabetes mellitus: the diabetes study of northern California (DISTANCE). Am J Hematol. 2010;85:57-61.

24. Kaze FF, Meto DT, Halle M-P, Ngogang J, Kengne A-P. Prevalence and determinants of chronic kidney disease in rural and urban Cameroonians: a cross-sectional study. BMC Nephrol. 2015;16:117

25. Chen CX, Li Y, Chan S, Chan K. Anaemia and type 2 diabetes: implications from a retrospectively studied primary care case series. Hong Kong Med J. 2013;19(3):214-21.

26. Ranil PK, Raman R, Rachepalli SR, Pal SS, Kulothungan V, Lakshmipathy P, Satagopan U, Kumaramanickavel G, Sharma T. Anemia and diabetic retinopathy in type 2 diabetes mellitus. J Assoc Physicians India. 2010;58:91-4.

27. Thomas MC. Anemia in diabetes: marker or mediator of microvascular disease? Nat Clin Pract Nephro. 2007;3:20-30.

28. Sinha N, Mishra TK, Singh T, Gupta N. Effect of iron deficiency anemia on hemoglobin A1c levels. Ann Lab Med. 2012;32:17-22.

\section{Submit your next manuscript to BioMed Central and we will help you at every step:}

- We accept pre-submission inquiries

- Our selector tool helps you to find the most relevant journal

- We provide round the clock customer support

- Convenient online submission

- Thorough peer review

- Inclusion in PubMed and all major indexing services

- Maximum visibility for your research

Submit your manuscript at www.biomedcentral.com/submit
Biomed Central 